\title{
applied
}

Applied Acoustics 63 (2002) 431-451

www.elsevier.com/locate/apacoust

\section{Indoor noise reduction index with open window}

\author{
C. Buratti* \\ Department of Industrial Engineering, University of Perugia, Via G. Duranti 1-A/4, 06125 Perugia, Italy
}

Received 20 November 2000; received in revised form 8 May 2001; accepted 17 May 2001

\begin{abstract}
Indoor noise is mainly caused by road and railway traffic, especially in summer time due to open windows. The presence of absorbent ceilings can help to reduce reverberating noise and the global mean acoustic level. The aim of this work is to define an index to evaluate the indoor noise reduction index (NRI) with open window; it is a function of the acoustic absorption coefficient of the room ceiling. It is evaluated by measurements in two reverberating rooms, which simulate the real conditions. In the emission room a noise source reproduces the road and railway noise. In the receiving room a microphone measures the noise level and its spectrum; the ceiling is treated with different absorption materials. A comparison between the values in absence and in presence of different materials and an evaluation of NRI are carried out. Experimental results are generalised and a theoretical expression of NRI is given. (C) 2002 Elsevier Science Ltd. All rights reserved.
\end{abstract}

\section{Introduction}

In recent years there has been a growing interest in noise pollution especially regarding big urban areas. It has been estimated that $20 \%$ of the European Union population is exposed to noise levels considered unacceptable by health experts because it can cause ailments and damage of various natures. The design of a building must also account for conditions of "well-being" noise level, ensuring adequate sound proofing from the outdoors and from adjacent rooms where the noise sources originate.

More often than not, intervention is needed in pre-existing situations where acceptable noise conditions are precarious such as near roads, railroads, airports,

\footnotetext{
* Tel.: + 39-75-585-3693; fax: + 39-75-585-3697.

E-mail address: cburatti@unipg.it
} 


\section{Nomenclature}

a absorption coefficient (-);

$A \quad$ absorbent unities $\left(\mathrm{m}^{2}\right)$;

C speed of sound $(\mathrm{m} / \mathrm{s})$;

$D \quad$ density of sound energy $\left(\mathrm{J} / \mathrm{m}^{3}\right)$;

ETD experimental theoretical difference (dBA);

$L \quad$ sound pressure level (dB, dBA);

$L_{\text {eq(A) }}$ weighted A continuum equivalent level (dBA)

NRC noise reduction coefficient $(-)$;

NRI noise reduction index (dBA);

$S \quad$ area $\left(\mathrm{m}^{2}\right)$;

$t_{\mathrm{m}} \quad$ mean free time (s);

$T$ reverberation time (s);

$v \quad$ train velocity $(\mathrm{km} / \mathrm{h})$;

$V \quad$ volume $\left(\mathrm{m}^{3}\right)$;

$W \quad$ sound power $(\mathrm{W})$;

$v \quad$ frequency (Hertz);

\section{Subscripts}

$0 \quad$ without false ceiling;

1 false ceiling with panel n. 1;

2 false ceiling with panel n. 2;

250 at 250 Hertz;

500 at 500 Hertz;

1000 at 1000 Hertz;

2000 at 2000 Hertz;

a absorbent;

(A) weighted A;

C ceiling;

e experimental;

f final;

g global;

$\mathrm{t}$ theoretical.

where the usual noise control techniques are not always sufficient; special interventions are then needed, such as installing high sound absorbent windows [1]. Outdoor noise control techniques neglected until now the problem of reducing noise in environments where there are open windows. This is a very common situation at our latitudes, where the climate in summertime makes opening windows necessary.

The Italian and European Regulations refer to noise emission limits in closed environments or to the characteristics of noise insulation in building or parts of 
buildings. The Decreto del Presidente del Consiglio dei Ministri (DPCM) 5 December 1997, on the definition of the passive noise requisites of buildings (in compliance with art. 3, comma 1 letter e of The Legge Quadro on Acoustic Pollution n. 447/95), establishes the minimum requisites of sound proof in building constructions, but they all consider closed windows. The UNI EN ISO 717-1 [2] defines some evaluation indexes of the insulation properties of airborne sounds of buildings and parts of buildings; the most significant is the evaluation index of the sound insulation power, indicated with the symbol $R_{\mathrm{w}}$. The description with single-numbered indexes of the acoustic properties of building elements makes up the European level standard and for this reason the aim of this paper is to attain a single-numbered index which characterizes the indoor noise reduction with open windows. The basic consideration made is that most of the noise that concerns people inside a room with open windows is due to not only a direct field, but also to a reverberating one. In particular, as concerns direct and reflected wave absorption, the contribution of the ceiling is significant; in fact the source (in this case road and railway traffic) is generally located beneath the open window. Therefore, a parameter was defined to evaluate the reduction of the weighted A continuum equivalent level produced by a sound proofing false ceiling for road and railway traffic noise.

Laboratory measurements were taken to determine the effect of installing a sound absorbent ceiling on the level of acoustic pressure in coupled reverberating rooms, connected through an opening, with different typologies of the false ceiling in the receiving room and the relative noise reduction was evaluated. A theoretical model was developed to predict the noise reduction and a comparison between the data experimentally attained and those evaluated by the theoretical model was made. Finally, a single-numbered index, named noise reduction index (NRI), able to quantify the entity of noise reduction with open windows for a certain type of material, was elaborated. The same procedure was applied even with closed windows; thereafter, all measurements were repeated and the results were generalized.

\section{Experimental facility}

All measurements were carried out at the Acoustic Laboratory of the Department of Industrial Engineering equipped with coupled reverberating rooms (Fig. 1). These are boxed structured with reinforced concrete walls of $0.40 \mathrm{~m}$ width; they are mechanically insulated from the outdoors and from one another and built in compliance with the ISO 140-1 [3]. The emission room has a net volume of $53.36 \mathrm{~m}^{3}$; a reinforced concrete section of the floor is of $4.60 \times 2.50=11.5 \mathrm{~m}^{2}$ dimensions and $0.12 \mathrm{~m}$ width: it is a removable floor used for testing insulation from trample noise. The receiving room has a net volume of $62.79 \mathrm{~m}^{3}$.

The walls and the ceiling of both rooms are plastered; the floor is of ceramic tiles. The doors are made of boxed metal filled with sand; the sealing gasket is of silicon rubber. The two rooms are mechanically insulated from each other by means of a layer of elastic material of $0.10 \mathrm{~m}$ width; they are placed on the foundation beams, with elastic material in between (neoprene), in order to dampen possible vibrations 


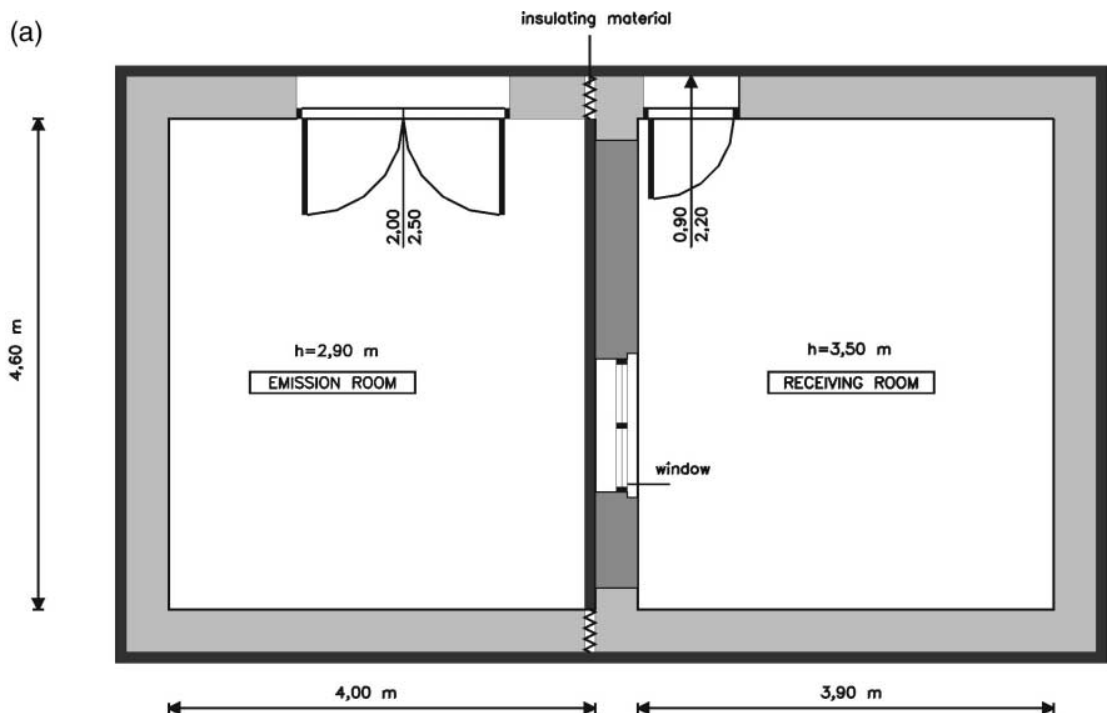

(b)

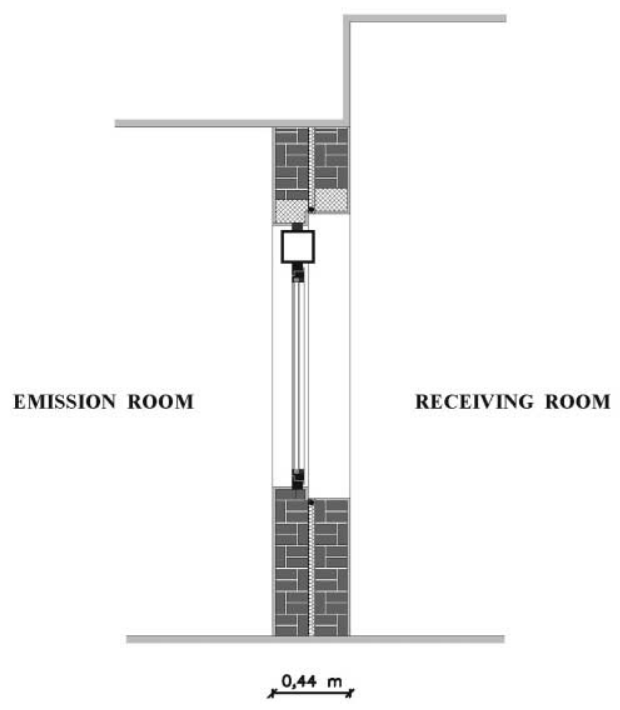

Fig. 1. The coupled reverberating rooms of the Laboratory of Acoustics of the Department of Industrial Engineering: (a) plan; (b) section.

brought on by the load-bearing structure of the building. The opening between the two rooms has $4.20 \times 2.50 \mathrm{~m}$ dimensions, at a total area of $10.50 \mathrm{~m}^{2}$. During testing, it is closed by a wall made of two layers of $0.18 \mathrm{~m}$ width each in brick, with in between a layer of rock wool of $0.03 \mathrm{~m}$ width. The walls are externally coated with reflecting plaster. On the wall there is a window with $\mathrm{H} \times \mathrm{L}=1.25 \times 1.50 \mathrm{~m}$ dimensions. 
The measuring system consists of an omni-directional noise source with dodecahedral shape, designed and built at the Acoustic Laboratory of the Department of Industrial Engineering. The source was verified at emission uniformity as established by the ISO 140/3 [4] and is supplied by a model SU-A900 amplifier. It is linked to a digital recorder DAT (Digital Audio Tape-Corder) SONY model TCD-D7 that reproduces the noise recorded on a tape.

The capacitor microphones used to detect the acoustic signals (model UC53A by RION) are equipped by the respective preamplifiers to be linked to the data acquisition system.

The acquisition and elaboration data are carried out by PC with a card for acquiring acoustic signals, model OROS AU22 of $01 \mathrm{~dB}$. The card allows us to acquire two distinct acoustic signals at the same time and to carry out the necessary elaboration by a specific programme. The measuring system is in Class 1 and complies with the technical norms IEC 225/1966, IEC 225/1979 and IEC 804/1995.

The ability to repeat and reproduce the measurements has been evaluated in compliance with UNI EN ISO 140-2 [5] and UNI CEI EN 45001 [6].

\section{Noise sources}

Three external situations were simulated in the emission room: noises produced by road traffic, by low speed railway traffic and high speed railway traffic. The respective noise spectra were recorded along the main roads and railways in the city of Perugia and outskirts and were later reproduced in the Laboratory. At the same time, a bibliographical research was done so as to gather several spectra established in the European Norms and then to compare them to the ones recorded.

There are several rules that try to define a normalized spectrum of road and railway traffic [7-10]. In these, all spectra are defined in A pondered band levels and are normalized at $0 \mathrm{~dB}(\mathrm{~A})$, so that a global reference level needs to be defined.

For road traffic the normalized spectrum proposed by the prEN 1793-3 European Norm [9] was chosen, and the global level (A) proposed by the Società Autostrade (Italian Motorways Company) was fixed at $83.8 \mathrm{~dB}(\mathrm{~A})$. The spectrum of road traffic was measured in Via Mario Angeloni, one of the busiest roads in the city of Perugia, on a one- way straight road with three lanes and at a constant slope of $5 \%$ : the vehicles travel up the slope and the traffic flow is continuous, without traffic lights or pedestrian crossings.

For railway traffic, the normalized spectra of the Swedish NT ACOU 062 Norm [8] was selected; also in this case, a global (A) level found in literature was fixed: a closed environment was assumed to be located at a $30 \mathrm{~m}$ distance from the railway axis and the $L_{\mathrm{g}(\mathrm{A})}$ was calculated in a function of the train velocity according to the following relation (valid for bolted tracks):

$$
L_{\mathrm{g}(\mathrm{A})}=81+30 \log _{10}\left(v / v_{0}\right) \mathrm{dB}(\mathrm{A})
$$

$\left(v_{0}\right.$ reference velocity $\left.=60 \mathrm{~km} / \mathrm{h}\right)$. 


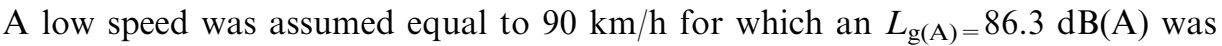

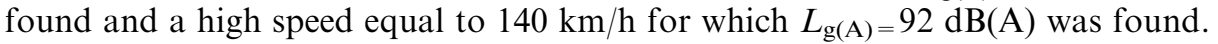

The actual noise produced by a train was recorded along the Terontola-Chiusi line, near Ferretto, where there are four perfectly horizontal bolted tracks.

The comparisons between the recorded spectra and the ones reproduced in the emission room are in good agreement (see Fig. 2). Fig. 3 synthetically shows the

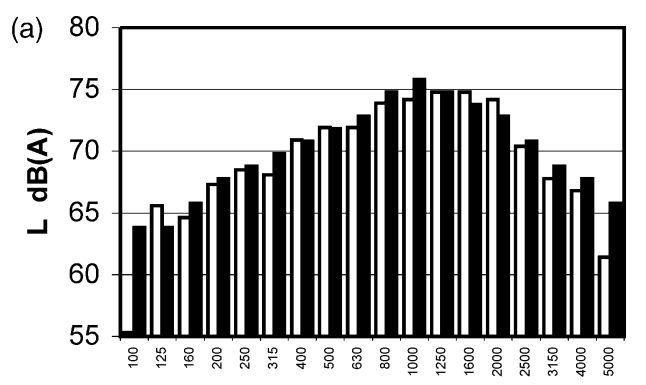

\section{$\square$ mean experimental \\ spectrum in the \\ emission room}

口prEN 1793-3

(Hertz)

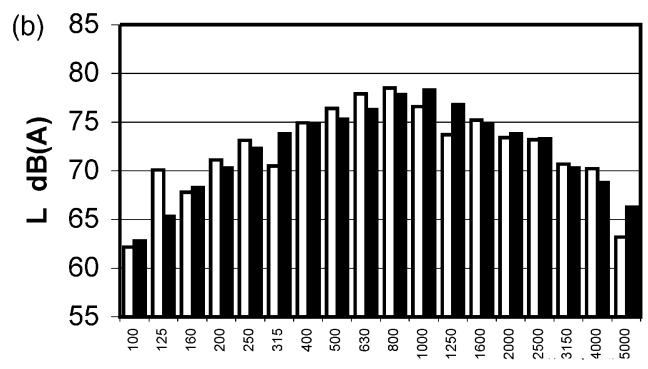

$\square$ mean experimental

spectrum in the

emission room

-NT ACOU 062

(Hertz)

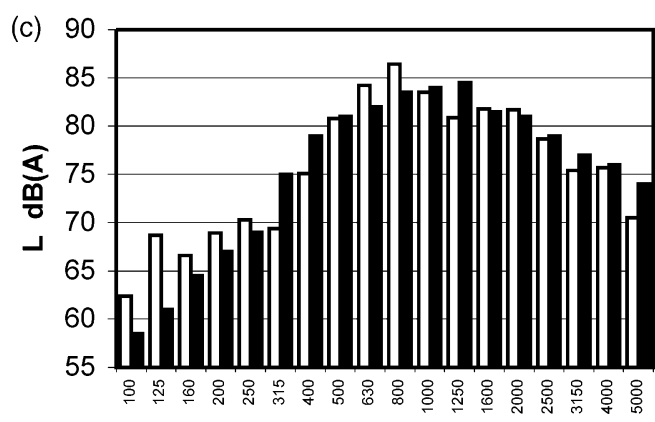

$\square$ mean experimental

spectrum in the

emission room

NT ACOU 062

(Hertz)

Fig. 2. Comparison between the spectra reproduced and detected in the emission room and the reference ones: (a) road traffic (PrEN 1793-3); (b) low speed railway traffic (NT Acou 062); (c) high speed railway traffic (NT Acou 062). 


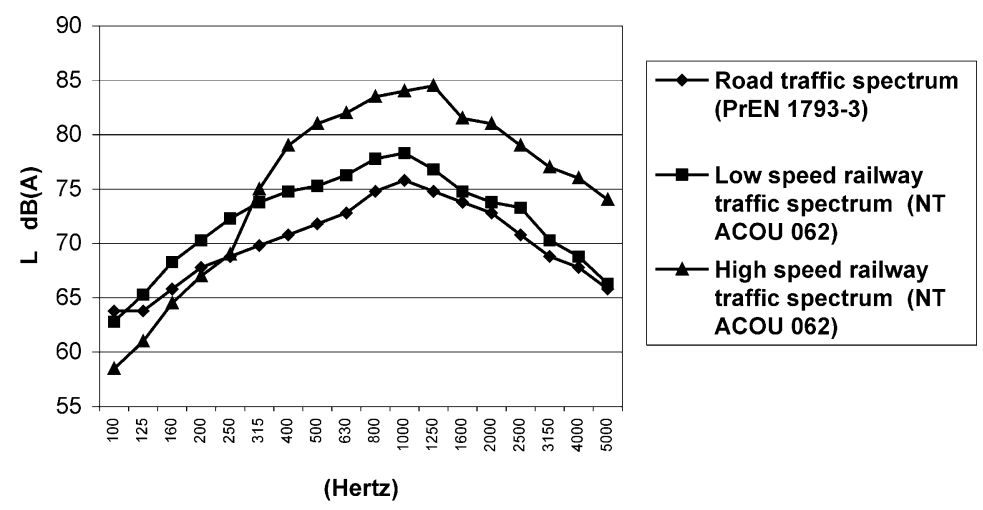

Fig. 3. Comparison of the road and railway noise spectra.

reference spectra for road and railway traffic chosen for laboratory reproduction; Table 1 shows the relative data.

Spectra were reproduced by the omni-directional source in the emission reverberating room, so the directional characteristics of the real sources are not considered and the sound proofing material location inside the receiving room is not important. In this work the sound proofing material is placed on the ceiling, where in the real situations the direct field is incident. To leave out of consideration the particular characteristics of a directional source, an omni-directional one has been chosen, which can always be reproduced in laboratory tests. A directional source and an absorption treatment of the emission room could be employed in future work, to evaluate the influence of the directional characteristics of the source on the experimental results.

\section{Measurements methodology}

To evaluate noise reduction due to the installation of sound proofing ceilings inside a room, different situations were investigated. The measurements were carried out in the following conditions:

A) Measurements with open window

B) Measurements with closed window
Al with road traffic

A2 with low speed railway traffic

A3 with high speed railway traffic

B1 with road traffic

B2 with low speed railway traffic

B3 with high speed railway traffic

First of all, the sound pressure levels and the spectra of noise in the receiving environment, when there was no false ceiling, were measured, so a reference state could be fixed; all the measurements were then repeated twice, corresponding to the installation of two kinds of false ceiling. 
Table 1

Comparison among the data concerning the spectra measured in the emission room and the reference spectra

\begin{tabular}{|c|c|c|c|c|c|c|c|c|c|}
\hline \multirow[t]{2}{*}{$v(\mathrm{~Hz})$} & \multicolumn{3}{|c|}{ Road traffic } & \multicolumn{3}{|c|}{ Low speed railway traffic } & \multicolumn{3}{|c|}{ High speed railway traffic } \\
\hline & $\begin{array}{l}\text { MES } \\
{[\mathrm{dB}(\mathrm{A})]^{\mathrm{a}}}\end{array}$ & $\begin{array}{l}\operatorname{PrEN} \\
1793-3 \\
{[\mathrm{~dB}(\mathrm{~A})]}\end{array}$ & $\begin{array}{l}\mathrm{D} \\
{[\mathrm{dB}(\mathrm{A})]^{\mathrm{b}}}\end{array}$ & $\begin{array}{l}\text { MES } \\
\mathrm{dB}(\mathrm{A})\end{array}$ & $\begin{array}{l}\text { NT Acou } \\
062 \text { dB(A) }\end{array}$ & $\begin{array}{l}\mathrm{D} \\
\mathrm{dB}(\mathrm{A})\end{array}$ & $\begin{array}{l}\text { MES } \\
\text { dB(A) }\end{array}$ & $\begin{array}{l}\text { NT Acou } \\
062 \text { dB(A) }\end{array}$ & $\begin{array}{l}\mathrm{D} \\
\mathrm{dB}(\mathrm{A})\end{array}$ \\
\hline 100 & 55.3 & 63.8 & -8.5 & 62.2 & 62.8 & -0.6 & 62.4 & 58.5 & +3.9 \\
\hline 125 & 65.6 & 63.8 & +1.8 & 70.1 & 65.3 & +4.8 & 68.7 & 61.0 & +7.7 \\
\hline 160 & 64.6 & 65.8 & -1.2 & 67.8 & 68.3 & -0.5 & 66.6 & 64.5 & +2.1 \\
\hline 200 & 67.3 & 67.8 & -0.5 & 71.1 & 70.3 & +0.8 & 68.9 & 67.0 & +1.9 \\
\hline 250 & 68.5 & 68.8 & -0.3 & 73.1 & 72.3 & +0.8 & 70.3 & 69.0 & +1.3 \\
\hline 315 & 68.1 & 69.8 & -1.7 & 70.5 & 73.8 & -3.3 & 69.4 & 75.0 & -5.6 \\
\hline 400 & 70.9 & 70.8 & +0.1 & 74.9 & 74.8 & +0.1 & 75.1 & 79.0 & -3.9 \\
\hline 500 & 71.9 & 71.8 & +0.1 & 76.4 & 75.3 & +1.1 & 80.8 & 81.0 & -0.2 \\
\hline 630 & 71.9 & 72.8 & -0.9 & 77.9 & 76.3 & +1.6 & 84.2 & 82.0 & +2.2 \\
\hline 800 & 73.9 & 74.8 & -0.9 & 78.5 & 77.8 & +0.7 & 86.4 & 83.5 & +2.9 \\
\hline 1000 & 74.2 & 75.8 & -1.6 & 76.6 & 78.3 & -1.7 & 83.5 & 84.0 & -0.5 \\
\hline 1250 & 74.8 & 74.8 & 0.0 & 73.7 & 76.8 & -3.1 & 80.9 & 84.5 & -3.6 \\
\hline 1600 & 74.8 & 73.8 & +1.0 & 75.2 & 74.8 & +0.4 & 81.8 & 81.5 & +0.3 \\
\hline 2000 & 74.2 & 72.8 & +1.4 & 73.4 & 73.8 & -0.4 & 81.7 & 81.0 & +0.7 \\
\hline 2500 & 70.4 & 70.8 & +0.4 & 73.2 & 73.3 & -0.1 & 78.7 & 79.0 & -0.3 \\
\hline 3150 & 67.8 & 68.8 & -1.0 & 70.7 & 70.3 & +0.4 & 75.4 & 77.0 & -1.6 \\
\hline 4000 & 66.8 & 67.8 & -1.0 & 70.2 & 68.8 & +1.4 & 75.7 & 76.0 & -0.3 \\
\hline 5000 & 61.4 & 65.8 & -4.4 & 63.2 & 66.3 & -3.1 & 70.5 & 74.0 & -3.5 \\
\hline$L_{\mathrm{g}} \mathrm{dB}(\mathrm{A})$ & 83.5 & 83.8 & +0.3 & 86.2 & 86.3 & -0.1 & 92.2 & 92.0 & +0.2 \\
\hline
\end{tabular}

a $\mathrm{MES}=$ mean experimental spectrum.

b $\mathrm{D}=$ difference between MES and the reference spectra.

The aim of the experimental testing phase was to evaluate the effect of the false ceiling with open windows; it was, anyhow, thought useful to repeat the measurements with closed windows, to see the possible influence of the false ceiling.

The acoustic absorption coefficient of the false ceilings was measured; reference was made to EN ISO 354 [11]. The reverberation time was measured placing the source and microphone as indicated in Fig. 4. The calculation of the acoustic absorption coefficient was carried out on the basis of Sabine's equation [11].

The spectrum and the weighted A continuum equivalent level were measured in the receiving room placing the source in the emission one in the five points established in the UNI EN ISO 140-3 [3]. The microphones were positioned in the receiving room to make mapping possible; then a regular $50 \times 50 \mathrm{~cm}$ shape measuring point grid was fixed; the configuration of the source-microphones and measuring grid are illustrated in Fig. 5(a) and (b).

The microphone is $1.50 \mathrm{~m}$ high and represents the average height at which the human ear is at. The source, linked to the DAT digital recorder connected to the amplifier, emits the road traffic noise which is detected and analysed in point $\mathrm{E}$ of the emission room (see Fig. 5); in the receiving room the $L_{\text {eq(A) }}$ is measured in every point of the measurement grid. The source is then moved and each time a relative 


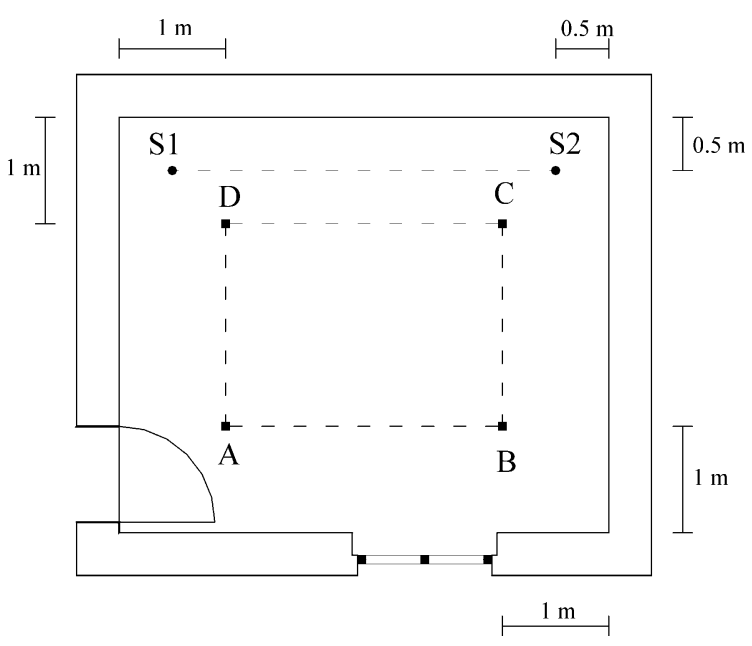

Fig. 4. Position of the source and the microphones when measuring $T$.

mapping of the position of the source is made. At the end of the measurement, the energetic average of $L_{\mathrm{eq}}(\mathrm{A})$ is carried out in each point of the grid and a mapping is attained in the receiving room. This procedure is repeated for the different traffic spectra and for the two typologies of false ceiling.

For each source position, measurements of the spectrum of noise in five important points of the grid are performed $(1,8,29,49$ and 56). By averaging the spectra found in the five points, a mean spectrum is found for the receiving room.

\section{Results}

The values of reverberation time in the three examined situations (room without false ceiling, with the first false ceiling and with the second false ceiling) are reported in Table 2. The trends of the sound absorption coefficient for the two types of panels were attained by calculating the absorption unities vs. frequency and are reported in Fig. 6. The first type of panel has a very low acoustic absorption coefficient at all frequencies ranging between 0.1 and 0.2 . The second type of panel has a low acoustic absorption coefficient when frequencies are low and gradually increases as the frequency increases; it varies between a minimum of 0.15 at $100 \mathrm{~Hz}$ and a maximum of 0.65 at $5000 \mathrm{~Hz}$.

The measurements of weighted A continuum equivalent level at the grid points have been used to make the noise maps with the acoustic pressure iso-level curves, relative to the different experimental situations. A synthesis of the experimental results is reported in Table 3.

The results in the case of the measurements when windows are open are shown in Fig. 7 and Table 4, relating to road traffic. When the false ceiling is not installed (Fig. 7a), the maximum value of $L_{\mathrm{eq}(\mathrm{A})}$ is found in points 61 and 62, exactly corresponding to 
(a)

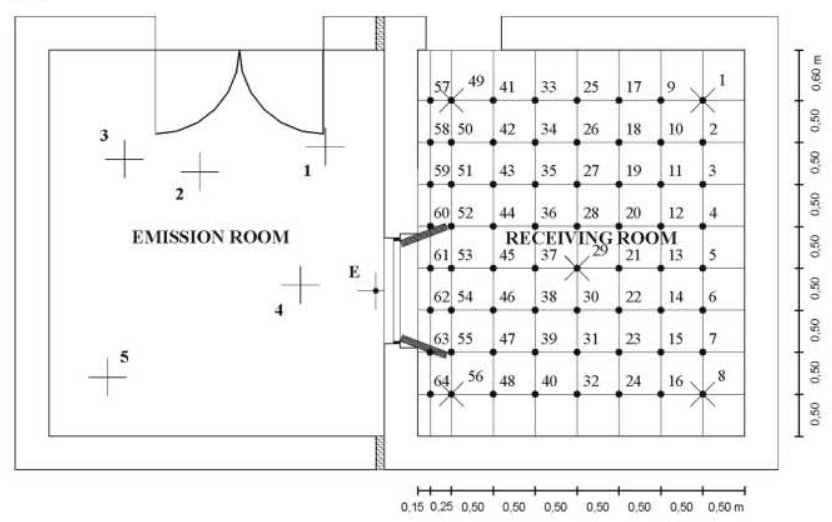

(b)

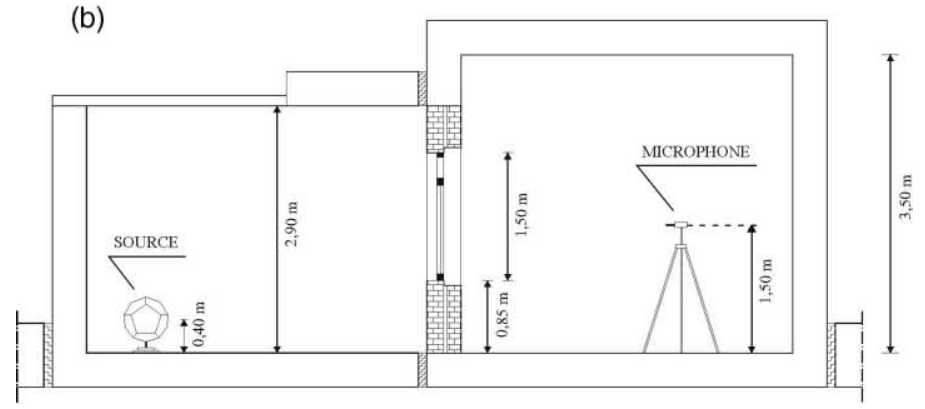

(c)

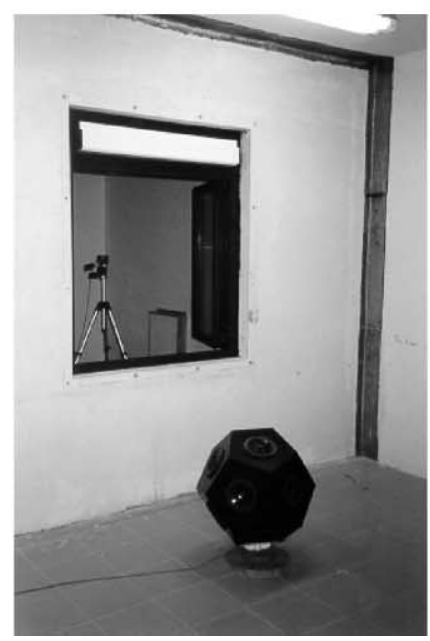

Fig. 5. Position of the source and the microphones when measuring $L_{\text {eq(A) }}$; plant; (b) section; (c) view. 
Table 2

Reverberation times and absorbent unities in the different examined situations and absorption coefficient of the two kinds of false ceiling

\begin{tabular}{llllllllll}
\hline$v(\mathrm{~Hz})$ & $T_{0}(\mathrm{~s})$ & $T_{1}(\mathrm{~s})$ & $T_{2}(\mathrm{~s})$ & $A_{0}\left(\mathrm{~m}^{2}\right)$ & $A_{1}\left(\mathrm{~m}^{2}\right)$ & $A_{2}\left(\mathrm{~m}^{2}\right)$ & $a$ Plaster & $a$ Panel n. 1 & $a$ Panel n. 2 \\
\hline 100 & 4.88 & 2.07 & 2.16 & 2.07 & 4.65 & 4.46 & 0.012 & 0.16 & 0.14 \\
125 & 3.02 & 1.26 & 1.37 & 3.35 & 7.64 & 7.04 & 0.013 & 0.25 & 0.22 \\
160 & 2.12 & 1.15 & 1.19 & 4.77 & 8.38 & 8.12 & 0.014 & 0.21 & 0.20 \\
200 & 1.73 & 0.95 & 0.80 & 5.85 & 10.14 & 12.05 & 0.014 & 0.25 & 0.36 \\
250 & 1.48 & 0.91 & 0.72 & 6.84 & 10.58 & 13.39 & 0.015 & 0.22 & 0.38 \\
315 & 1.39 & 1.01 & 0.82 & 7.28 & 9.54 & 11.79 & 0.017 & 0.14 & 0.27 \\
400 & 1.57 & 1.13 & 0.79 & 6.45 & 8.52 & 12.17 & 0.018 & 0.13 & 0.34 \\
500 & 1.62 & 1.14 & 0.86 & 6.25 & 8.45 & 11.15 & 0.020 & 0.14 & 0.29 \\
630 & 1.80 & 1.31 & 0.72 & 5.62 & 7.35 & 13.33 & 0.023 & 0.12 & 0.45 \\
800 & 2.02 & 1.46 & 0.71 & 5.01 & 6.60 & 13.51 & 0.027 & 0.12 & 0.50 \\
1000 & 2.03 & 1.52 & 0.71 & 4.99 & 6.34 & 13.50 & 0.030 & 0.11 & 0.50 \\
1250 & 2.01 & 1.49 & 0.69 & 5.04 & 6.46 & 14.01 & 0.033 & 0.11 & 0.53 \\
1600 & 1.90 & 1.50 & 0.76 & 5.33 & 6.42 & 12.67 & 0.037 & 0.10 & 0.45 \\
2000 & 1.92 & 1.46 & 0.79 & 5.27 & 6.60 & 12.18 & 0.040 & 0.11 & 0.43 \\
2500 & 1.78 & 1.40 & 0.74 & 5.68 & 6.88 & 13.00 & 0.043 & 0.11 & 0.45 \\
3150 & 1.70 & 1.32 & 0.66 & 5.96 & 7.30 & 14.70 & 0.047 & 0.12 & 0.53 \\
4000 & 1.54 & 1.23 & 0.59 & 6.57 & 7.83 & 16.34 & 0.050 & 0.12 & 0.59 \\
5000 & 1.32 & 1.07 & 0.51 & 7.67 & 9.00 & 18.73 & 0.053 & 0.13 & 0.67 \\
\hline
\end{tabular}
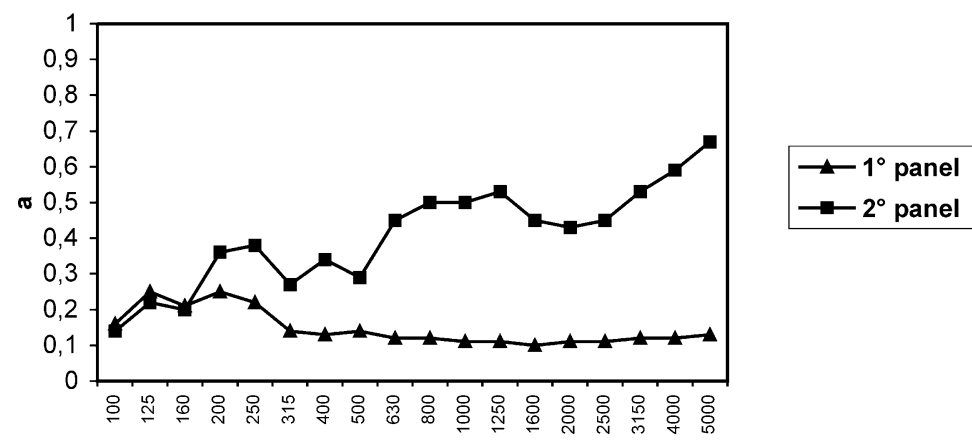

(Hertz)

Fig. 6. Trend of the acoustic absorption coefficient of the two types of panels used in testing.

where the open window is and is equal to $81.1 \mathrm{~dB}(\mathrm{~A})$; it decreases gradually as the window gets farther and gets closer to the walls of the room up until $76.5 \mathrm{~dB}(\mathrm{~A})$. With the first type of false ceiling the maximum value of $L_{\text {eq(A) }}$ is $81 \mathrm{~dB}(\mathrm{~A})$; the values of $L_{\text {eq(A) }}$ decrease gradually until $75.5 \mathrm{~dB}(\mathrm{~A})$ (Fig. 7b). The difference of mean A pondered continuum equivalent level prompted by the introduction of the false ceiling with the first type of panel is equal to $0.9 \mathrm{~dB}(\mathrm{~A})$. With the second type of sound absorption panel (Fig. 7c) the maximum value of $L_{\mathrm{eq}}(\mathrm{A})$ is equal to 80.2 $\mathrm{dB}(\mathrm{A})$, the minimum value is $72.5 \mathrm{~dB}(\mathrm{~A})$. In this case, the mean value of the difference 
(a)

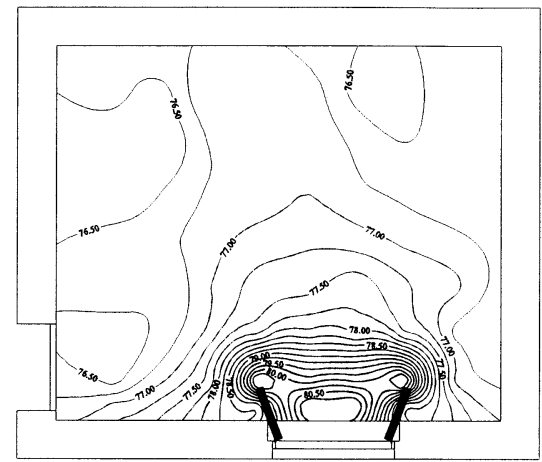

(b)

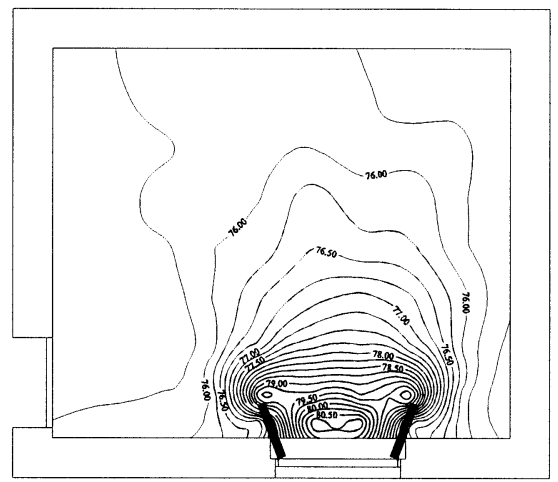

(c)

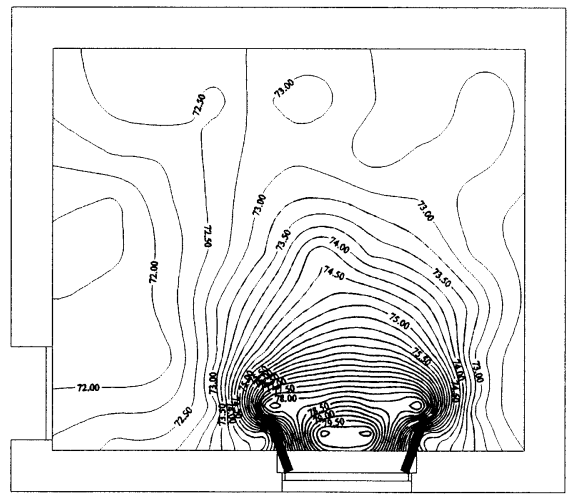

Fig. 7. Trend of $L_{\text {eq(A) }}$ when windows are open in the receiving room with road traffic; (a) without false ceiling; (b) false ceiling with panel n. 1; (c) false ceiling with panel n. 2 .

is equal to $3.7 \mathrm{~dB}(\mathrm{~A})$, which is a significant result; the second type of panel has in fact a sound absorption coefficient much higher at medium to high frequencies.

Similar trends of the sound pressure level in the receiving room can be found for railway traffic at low and high speed; therefore, for the sake of brevity, the noise 
Table 3

Syntheses of the experimental results

\begin{tabular}{|c|c|c|c|c|c|c|}
\hline & $\begin{array}{l}\text { Mean } L_{\mathrm{eq}} \\
\text { emission } \\
\text { room } \\
{[\mathrm{dB}(\mathrm{A})]}\end{array}$ & $\begin{array}{l}\text { Mean } L_{\mathrm{eq} 0}{ }^{\mathrm{a}} \\
\text { receiving } \\
\text { room } \\
{[\mathrm{dB}(\mathrm{A})]}\end{array}$ & $\begin{array}{l}\text { Mean } L_{\mathrm{eq} 1}{ }^{\mathrm{b}} \\
\text { receiving } \\
\text { room } \\
{[\mathrm{dB}(\mathrm{A})]}\end{array}$ & $\begin{array}{l}\text { Mean } L_{\mathrm{eq} 2}{ }^{\mathrm{c}} \\
\text { receiving } \\
\text { room } \\
{[\mathrm{dB}(\mathrm{A})]}\end{array}$ & $\begin{array}{l}\text { Mean } \Delta L_{1}= \\
L_{\mathrm{eq} 0}-L_{\mathrm{eq} 1} \\
{[\mathrm{~dB}(\mathrm{~A})]}\end{array}$ & $\begin{array}{l}\text { Mean } \Delta \mathrm{L}_{2}= \\
L_{\mathrm{eq} 0}-L_{\text {eq2 }} \\
{[\mathrm{dB}(\mathrm{A})]}\end{array}$ \\
\hline \multicolumn{7}{|l|}{ Open window } \\
\hline Road traffic & 83.5 & 76.8 & 75.9 & 73.1 & 0.9 & 3.7 \\
\hline $\begin{array}{l}\text { Low speed } \\
\text { railway traffic }\end{array}$ & 86.2 & 80.0 & 79.1 & 76.2 & 0.9 & 3.8 \\
\hline $\begin{array}{l}\text { High speed } \\
\text { railway traffic }\end{array}$ & 92.2 & 85.9 & 85.1 & 81.3 & 0.8 & 4.6 \\
\hline \multicolumn{7}{|l|}{ Closed window } \\
\hline Road traffic & 83.5 & 57.5 & 54.5 & 53.6 & 3.0 & 3.9 \\
\hline $\begin{array}{l}\text { Low speed } \\
\text { railway traffic }\end{array}$ & 86.2 & 60.7 & 58.0 & 56.8 & 2.7 & 3.9 \\
\hline $\begin{array}{l}\text { High speed } \\
\text { railway traffic }\end{array}$ & 92.2 & 63.5 & 62.0 & 58.8 & 1.5 & 4.7 \\
\hline
\end{tabular}

${ }^{\text {a }} L_{\text {eq } 0}=$ weighted A continuum equivalent level without false ceiling.

b $L_{\text {eq } 1}=$ weighted A continuum equivalent level with panel n. 1 .

${ }^{\text {c }} L_{\text {eq2 }}=$ weighted A continuum equivalent level with panel n. 2 .

Table 4

Comparison between the mean spectrum detected in the empty receiving room and with the types of false ceiling for road traffic

\begin{tabular}{llllll}
\hline$v(\mathrm{~Hz})$ & $\begin{array}{l}\text { Mean spectrum } \\
\text { receiving room } \\
\text { without false } \\
\text { ceiling [dB(A)] }\end{array}$ & $\begin{array}{l}\text { Mean spectrum } \\
\text { receiving room } \\
\text { with panel n. } 1\end{array}$ & $\begin{array}{l}\Delta L_{\text {eq }}[\mathrm{dB}(\mathrm{A})] \\
\text { panel n. 1 }\end{array}$ & $\begin{array}{l}\text { Mean spectrum } \\
\text { receiving room } \\
\text { with panel n. 2 } \\
\text { [dB(A)] }\end{array}$ & $\begin{array}{l}\Delta L_{\text {eq }} \text { [dB(A)] } \\
\text { panel n. 2. }\end{array}$ \\
\hline 100 & 52.4 & 49.5 & 2.9 & 47.8 & \\
125 & 62.9 & 55.2 & 7.7 & 56.1 & 4.7 \\
160 & 56.7 & 54.3 & 2.4 & 53.1 & 6.8 \\
200 & 61.2 & 59.0 & 2.2 & 58.9 & 3.6 \\
250 & 62.2 & 59.8 & 2.5 & 60.3 & 2.3 \\
315 & 61.0 & 59.1 & 1.9 & 59.0 & 2.0 \\
400 & 62.5 & 61.4 & 1.0 & 60.7 & 2.0 \\
500 & 64.2 & 63.3 & 0.9 & 62.6 & 1.8 \\
630 & 65.9 & 65.4 & 0.5 & 62.8 & 3.6 \\
800 & 67.1 & 66.7 & 0.3 & 63.4 & 3.6 \\
1000 & 68.1 & 67.9 & 0.2 & 63.6 & 4.5 \\
1250 & 68.2 & 67.5 & 0.7 & 63.6 & 4.6 \\
1600 & 67.8 & 66.9 & 0.8 & 63.8 & 3.9 \\
2000 & 67.1 & 65.9 & 1.2 & 62.7 & 4.3 \\
2500 & 62.8 & 62.6 & 0.2 & 58.6 & 4.1 \\
3150 & 59.8 & 59.2 & 0.6 & 55.5 & 4.3 \\
4000 & 58.5 & 57.9 & 0.5 & 54.3 & 4.2 \\
5000 & 52.6 & 51.5 & 1.1 & 48.7 & 3.9 \\
$L_{\mathrm{g}}$ & 76.8 & 75.9 & 0.9 & 73.1 & 3.7 \\
\hline
\end{tabular}


maps relating to railway traffic are not reported. For low speed railway traffic, when the false ceiling is not installed, a maximum value of $L_{\text {eq(A) }}$ equal to $84.5 \mathrm{~dB}(\mathrm{~A})$ and a minimum of about $80 \mathrm{~dB}(\mathrm{~A})$ are found. With the first type of sound absorption panel, the mean value of the difference is equal to $0.9 \mathrm{~dB}(\mathrm{~A})$ as in the case of road traffic; with the second type, the mean value of the difference is equal to $3.8 \mathrm{~dB}(\mathrm{~A})$. In the case of high-speed railway noise, the absolute values of $L_{\mathrm{eq}}$ are greater (around $90 \mathrm{~dB}(\mathrm{~A})$ near the open window). The decrease in the mean values due to the installation of the false ceiling are respectively $0.8 \mathrm{~dB}(\mathrm{~A})$ with the first type of panel and $4.6 \mathrm{~dB}(\mathrm{~A})$ with the second type.

The measurements of the noise spectrum detected in the five important points of the grid $(1,8,29,49,56)$ are reported in Fig. 8(a) and (b); it shows the trend of the differences in level attained with both types of false ceiling vs. the frequency, in the three situations of traffic. The same figures show the trend of the absorption coefficient of the two panels; when comparing, it can be seen that at the same frequencies, the reduction is as high as the absorption coefficient of the material (except for the low frequencies, when there are resonance phenomena). This is important since, once the
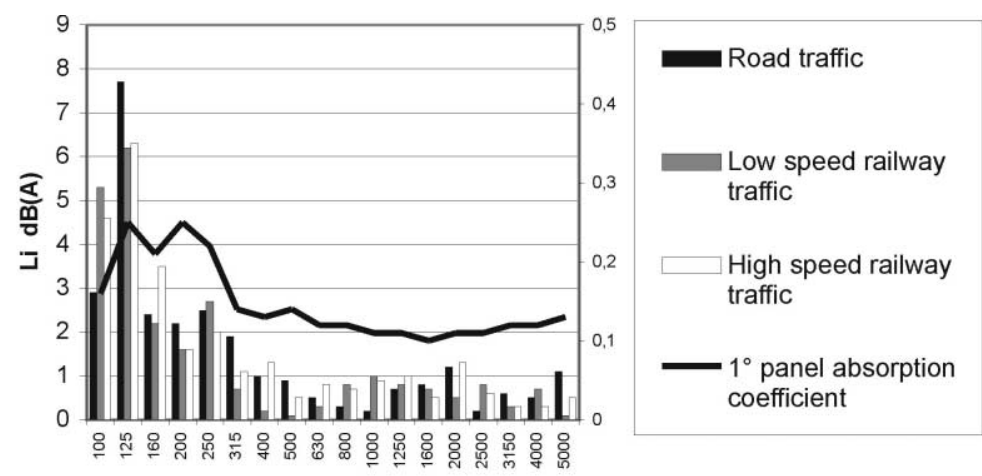

(Hertz)
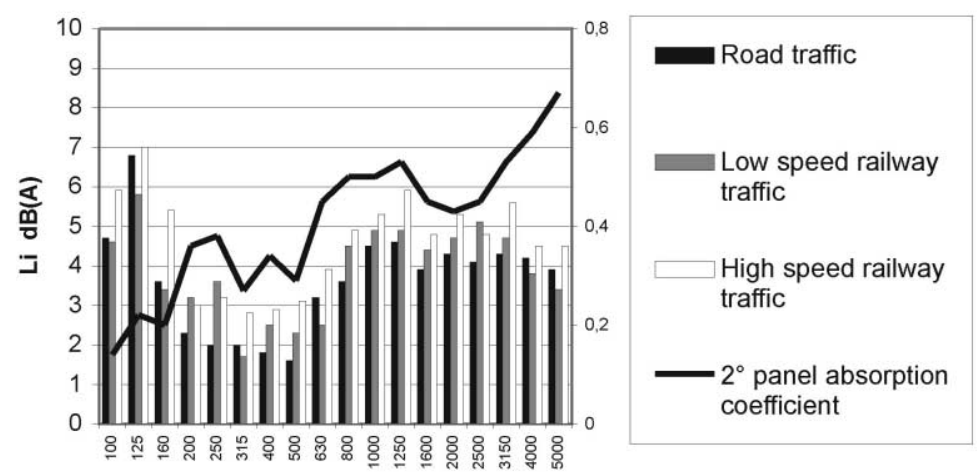

(Hertz)

Fig. 8. Trend of the absorption coefficient of the false ceiling and of the noise reduction in the three traffic conditions vs. frequency: (a) false ceiling with panel n. 1; (b) false ceiling with panel n. 2. 
noise spectrum is known, it is possible to choose the most useful type of material, that is to say the one with higher absorption coefficient in correspondence to the frequencies at which the noise pressure level is higher.

The measurements with closed windows were carried out to verify if the soundproof false ceiling was efficacious. The iso-level curve trend in the case of road traffic is shown in Fig. 9(a)-(c). The mean pondered A continuum equivalent level detected inside the empty receiving room is remarkably lower, due to the soundproofing effect of the window, therefore, the panels act at a lower equivalent level. The first type of panel increases its effícacy and its reduction ranges from 1.5 to $3 \mathrm{~dB}(\mathrm{~A})$; the highest reduction is attained for road traffic $[3 \mathrm{~dB}(\mathrm{~A})]$ whereas the lowest is at high speed railway traffic noise $[1.5 \mathrm{~dB}(\mathrm{~A})]$; this behaviour is due to the fact that the absorption coefficient of the first type of panel is higher at low frequencies and is lower instead at medium to high frequencies. The high-speed railway traffic noise has indeed a spectrum with values at low frequencies lower than the other two noise spectra. The second type of panel does not show an increase in efficacy as the first type and its reduction is very similar to the values that it had in the open window measurements, ranging from 3.9 and $4.7 \mathrm{~dB}(\mathrm{~A})$.

\section{Theoretical model}

In order to analytically evaluate the effect of the sound proof false ceiling on the noise induced by the transportation infrastructures, a theoretical model was elaborated which allows us to determine, once the spectrum of the incident noise on the ceiling is known, the reduction produced by the known acoustic properties of the material.

If $L_{0}$ is the indoor noise level before the false ceiling installation, with the hypothesis of steady-state, statistical acoustics and uniformity of sound energy density, the sound feeding power of the reverberating field is given by:

$$
W=\frac{D_{0} A_{0} c}{4}
$$

After the false ceiling installation, the sound feeding power of the reverberating field is the same; the corresponding density of sound energy is given by:

$$
D_{\mathrm{f}}=\frac{4 W}{c A_{\mathrm{f}}}
$$

so:

$$
D_{\mathrm{f}}=D_{0} \frac{A_{0}}{A_{\mathrm{f}}}
$$

and: 
(a)

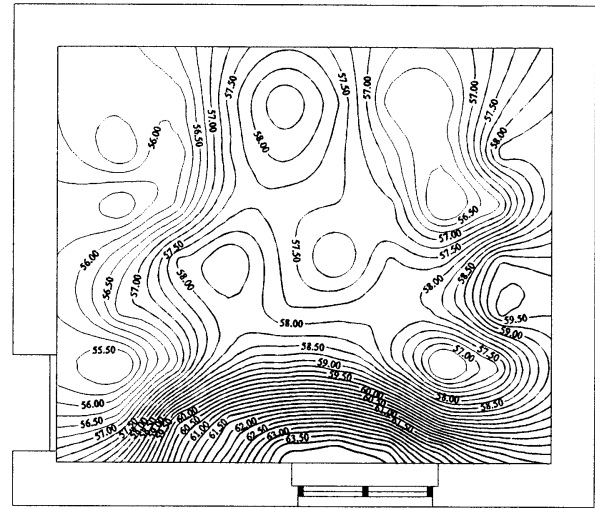

(b)

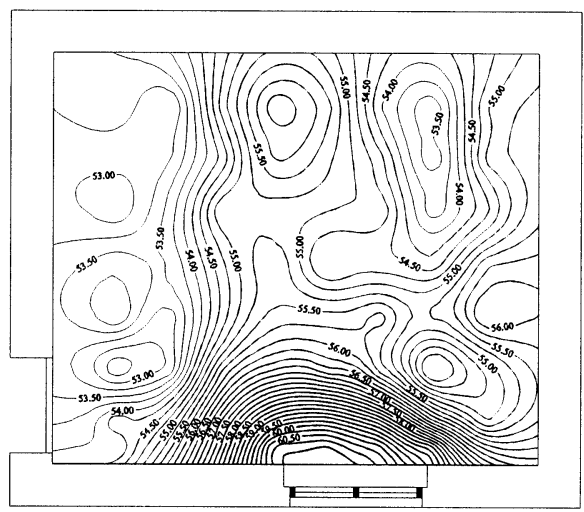

(c)

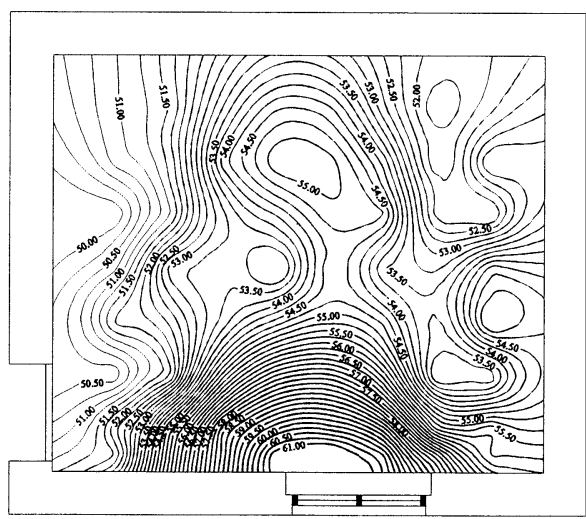

Fig. 9. Trend of $L_{\mathrm{eq}(\mathrm{A})}$ when windows are closed in the receiving room with road traffic: (a) without false ceiling; (b) false ceiling with panel n. 1; (c) false ceiling with panel n. 2. 


$$
L_{\mathrm{f}}=L_{0}+10 \log _{10} \frac{A_{0}}{A_{\mathrm{f}}}
$$

Considering the ceiling absorbent unities separately from the total absorbent unities, the relation (5) gives:

$$
L_{\mathrm{f}}=L_{0}-10 \log _{10}\left(1+\frac{A_{\mathrm{fC}}}{A_{0}}-\frac{A_{0 \mathrm{C}}}{A_{0}}\right)
$$

So, using the relation (6), it is possible to calculate the level $L_{\mathrm{f}}$ after the installation of a false ceiling with absorbent unities equal to $A_{\mathrm{fC}}$. The terms $10 \log _{10}\left(1+\frac{A_{\mathrm{fC}}}{A_{0}}-\frac{A_{0 \mathrm{C}}}{A_{0}}\right)$ have been calculated in each third octaves band in the range $100-5000 \mathrm{~Hz}$ for the first and second type of panel, once their absorption coefficients are known. A summary of the comparison results are reported in Table 5; the error made when using the theoretical model instead of the experimental data varies from a minimum of $-0.1 \mathrm{~dB}(\mathrm{~A})$ to a maximum of $+1.4 \mathrm{~dB}(\mathrm{~A})$. The sound level of the theoretical model is generally higher than the sound level of the experimental data, so that some safety is guaranteed.

\section{Noise reduction index}

The aim of this paper is to find a noise reduction index (NRI) that allows us to characterize a material in its noise reduction properties indoors, with either open or closed windows.

In order to synthetically but efficiently quantify both the theoretical and experimental noise reductions, two parameters $\mathrm{NRI}(\mathrm{t})$ and $\mathrm{NRI}(\mathrm{e})$ are introduced, so defined:

$$
\mathrm{NRI}(\mathrm{t})=\left[\Delta L(t)_{250}+\Delta L(t)_{500}+\Delta L(t)_{1000}+\Delta L(t)_{2000}\right] / 4
$$

\begin{tabular}{|c|c|c|c|c|c|c|}
\hline & \multicolumn{3}{|c|}{ Panel n. 1} & \multicolumn{3}{|c|}{ Panel n. 2} \\
\hline & $\begin{array}{l}\Delta L_{\mathrm{eq}(\mathrm{t})} \\
{[\mathrm{dB}(\mathrm{A})]}\end{array}$ & $\begin{array}{c}\Delta L_{\mathrm{eq}(\mathrm{e})} \\
{[\mathrm{dB}(\mathrm{A})]}\end{array}$ & $\begin{array}{l}\Delta L_{\mathrm{eq}(\mathrm{e}-\mathrm{t})} \\
{[\mathrm{dB}(\mathrm{A})]}\end{array}$ & $\begin{array}{l}\Delta L_{\mathrm{eq}(\mathrm{t})} \\
{[\mathrm{dB}(\mathrm{A})]}\end{array}$ & $\begin{array}{c}\Delta L_{\mathrm{eq}(\mathrm{e})} \\
{[\mathrm{dB}(\mathrm{A})]}\end{array}$ & $\begin{array}{l}\Delta L_{\text {eq(e-t) }} \\
{[\mathrm{dB}(\mathrm{A})]}\end{array}$ \\
\hline \multicolumn{7}{|l|}{ Open window } \\
\hline Road traffic & 0.9 & 0.9 & 0 & 3.5 & 3.7 & +0.2 \\
\hline Low speed railway traffic & 1.0 & 0.9 & -0.1 & 3.4 & 3.8 & +0.4 \\
\hline High speed railway traffic & 0.8 & 0.8 & 0 & 3.7 & 4.6 & +0.9 \\
\hline \multicolumn{7}{|l|}{ Closed window } \\
\hline Road traffic & 2.2 & 3.0 & +0.8 & 2.9 & 3.9 & +1.0 \\
\hline Low speed railway traffic & 2.1 & 2.7 & +0.6 & 2.9 & 3.9 & +1.0 \\
\hline High speed railway traffic & 1.4 & 1.5 & +0.1 & 3.4 & 4.7 & +1.4 \\
\hline
\end{tabular}

Table 5

Comparison between the reductions in global sound of the theoretical and experimental spectra 


$$
\mathrm{NRI}(e)=\left[\Delta L(e)_{250}+\Delta L(e)_{500}+\Delta L(e)_{1000}+\Delta L(e)_{2000}\right] / 4
$$

where $\Delta L$ (theoretical and experimental) are the level reductions found at the different frequencies when a false ceiling is installed.

As regards the soundproofing panels, an NRC index, defined as the arithmetical average of the sound absorption coefficients in the central frequency bands 250,500 , 1000 and $2000 \mathrm{~Hz}$, was chosen:

$$
\mathrm{NRC}=\frac{\left(a_{250}+a_{500}+a_{1000}+a_{2000}\right)}{4}
$$

This globally expresses the soundproofing properties of a material and is used when choosing and specifying the materials for noise control applications [12].

By applying (9) to the panels, the following is found: $\mathrm{NRC}_{1}=0.15$ and $\mathrm{NRC}_{2}=0.40$.

Table 6 shows the values of NRI(t) and NRI(e) calculated in all examined situations. The diagrams of these data are reported in Fig. 10 and show that NRI increases as NRC increases in all situations, so that the more soundproof the material the higher noise reduction is produced. The data then confirm that the error made when using the theoretical model increases as the sound coefficient of the material and of the NRC index increase, whether with open or closed windows.

To quantify the reliability of the theoretical model, a parameter can be introduced called ETD (experimental theoretical difference), defined as follows:

$$
\mathrm{ETD}=\mathrm{NRI}(\mathrm{e})-\mathrm{NRI}(\mathrm{t})
$$

For the first type of panel, ETD is around 0.2 dBA and does not show remarkable differences for the different types of spectra; for the second type of panel, the ETD values are on average greater, around $0.7 \mathrm{dBA}$ (see Table 7).

\begin{tabular}{|c|c|c|c|c|c|c|}
\hline Window & Panel & NRC & Traffic & NRI (e) & Mean NRI(e) & NRI $(t)$ \\
\hline \multirow[t]{6}{*}{ Open } & \multirow[t]{3}{*}{ n. 1} & \multirow[t]{3}{*}{0.15} & Road & 1.2 & \multirow{3}{*}{1.17} & \multirow{3}{*}{0.1} \\
\hline & & & Railway (low speed) & 1.1 & & \\
\hline & & & Railway (high speed) & 1.2 & & \\
\hline & \multirow[t]{3}{*}{ n. 2} & \multirow[t]{3}{*}{0.40} & Road & 3.1 & \multirow{3}{*}{3.73} & \multirow{3}{*}{3.1} \\
\hline & & & Railway (low speed) & 3.9 & & \\
\hline & & & Railway (high speed) & 4.2 & & \\
\hline \multirow[t]{6}{*}{ Closed } & \multirow[t]{3}{*}{ n. 1} & \multirow[t]{3}{*}{0.15} & Road & 1.2 & \multirow{3}{*}{1.17} & \multirow{3}{*}{1.0} \\
\hline & & & Railway (low speed) & 1.1 & & \\
\hline & & & Railway (high speed) & 1.2 & & \\
\hline & \multirow[t]{3}{*}{ n. 2} & \multirow[t]{3}{*}{0.40} & Road & 3.2 & \multirow{3}{*}{3.78} & \multirow{3}{*}{3.1} \\
\hline & & & Railway (low speed) & 3.9 & & \\
\hline & & & Railway (high speed) & 4.3 & & \\
\hline
\end{tabular}

Table 6

NRI(t) and NRI(e) values when windows are open and closed 


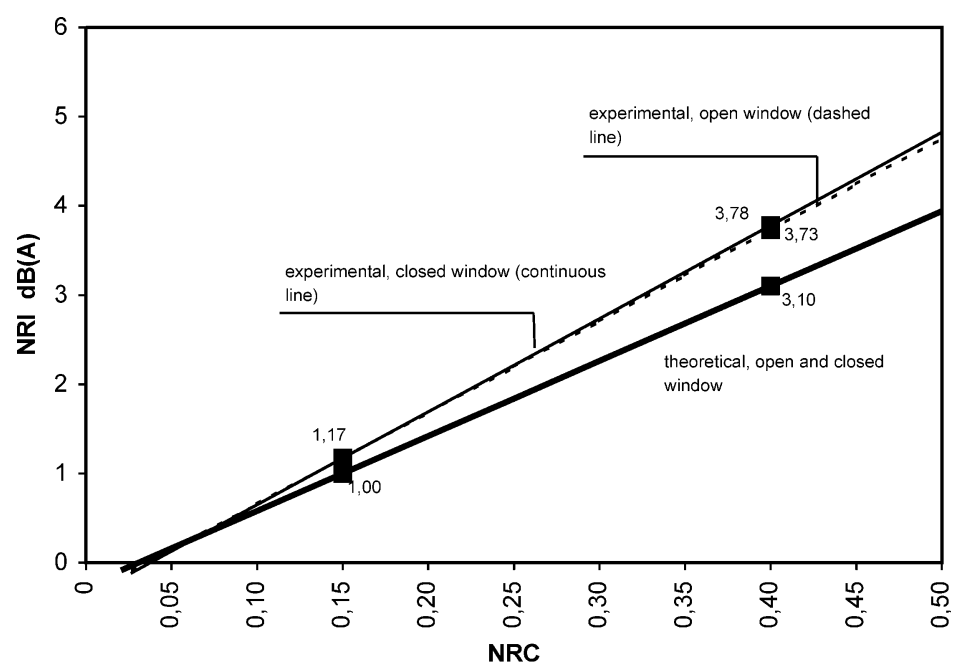

Fig. 10. NRI(t) and NRI(e) trends vs. NRC.

Table 7

Comparison between the values of the NRC and the ETD parameters, with three noise spectra and when measurements with either open or closed windows are carried out

\begin{tabular}{|c|c|c|c|c|}
\hline & \multicolumn{2}{|c|}{ Panel n. 1} & \multicolumn{2}{|c|}{ Panel n. 2} \\
\hline & NRC & $\operatorname{ETD}[\mathrm{dB}(\mathrm{A})]$ & NRC & $\operatorname{ETD}[\mathrm{dB}(\mathrm{A})]$ \\
\hline \multicolumn{5}{|l|}{ Open window } \\
\hline Road traffic & & 0.2 & & 0.0 \\
\hline Low speed railway traffic & 0.15 & 0.1 & 0.40 & 0.8 \\
\hline High speed railway traffic & & 0.2 & & 1.1 \\
\hline \multicolumn{5}{|l|}{ Closed window } \\
\hline Road traffic & & 0.2 & & 0.1 \\
\hline Low speed railway traffic & 0.15 & 0.1 & 0.40 & 0.8 \\
\hline High speed railway traffic & & 0.2 & & 1.2 \\
\hline Mean ETD [dB(A)] & & 0.17 & & 0.67 \\
\hline
\end{tabular}

In conclusion the error made when using the theoretical model instead of the measurements tends to increase with the absorption properties of the material, even if within acceptable ranges.

\section{Conclusions}

This work represents an original approach to the problem of the indoor noise reduction and points out a noise control technique not used until now. The para- 
meters that characterize walls and components have always referred to closed window rooms; on the contrary, it is important to improve acoustic comfort inside buildings in the seasons during which windows are often opened. So the problem of theoretically and experimentally determining road and railroad traffic noise reduction thanks to a soundproof false ceiling indoors with open windows was dealt with.

The actual situation was reproduced in the Acoustic Laboratory at the Department of Industrial Engineering by using the coupled reverberating rooms. Two types of soundproof panels were tested, each having very different acoustic characteristics. The first type has a low sound absorption coefficient for all $100-5000 \mathrm{~Hz}$ frequency range, the second type a medium to high absorption coefficient; the sound absorption coefficient of both types of panels was experimentally determined inside the receiving reverberating room, in compliance with EN ISO 354 [11].

A bibliographical research to gather normalized spectra of road and railway traffic noise to reproduce in the laboratory was done and among these a road traffic noise spectrum, a low speed railway noise spectrum and a high speed railway noise spectrum were chosen.

The spectra were reproduced using an omni-directional source placed in the emission room; in the receiving room a grid with 64 measurement points was traced. In each point a weighted A continuum equivalent level was detected for each of the three noise spectra emitted in the emission room and in five points also the spectra of the received noise.

All the measurement operations were before carried out with open windows and without a false ceiling in the receiving room, then with the first and second type of panel and were then repeated with closed windows.

The most immediate and significant finding to evaluate the soundproof efficacy of the false ceiling is the reduction in the global sound level, being equal to $1 \mathrm{~dB}(\mathrm{~A})$ circa for the first type of panel and circa $4 \mathrm{~dB}(\mathrm{~A})$ for the second type.

Also, a theoretical approach to the issue allowed us to determine the acoustic behaviour of the soundproof panels as regards the incident spectrum. The experimental results of the reduction in sound level in each band were compared with the corresponding theoretical values; the mean difference between them is a function of the acoustic absorption coefficient of the panel.

To characterize the sound absorption coefficient of a material, the noise reduction coefficient, NRC, was used; thereafter, the theoretical and experimental noise reduction index, NRI, was introduced, which represents the mean reduction of the level concerning the situation without false ceiling. When correlating NRI with NRC, it can be seen that NRI increases as NRC increases. It is, therefore, possible to assign a given material not only an NRC index that characterizes its sound absorption properties, but also an NRI index that characterizes its noise reduction properties with open or closed windows. So, the effect of the soundproof false ceiling on a certain incident spectrum can be known ahead of time, when the coefficient of the acoustic absorption of the panel is known.

The findings obtained experimentally are very encouraging since panels having higher absorption coefficients can also be used and since installation of soundproof panels even on lateral walls is possible. 


\section{Acknowledgements}

The Author thanks Dr. Massimo Palmerini for his precious collaboration in the measurements carried out.

\section{References}

[1] Cotana F. Experimental data and performances of new high sound insulation ventilating windows. Fort Lauderdale, FL: Internoise99. 6-8 December 1999.

[2] UNI EN ISO 717-1. Acoustics. Rating of sound insulation in buildings and of building elements, Airborne Sound Insulation, December 1997.

[3] ISO/FDIS 140-1. Acoustics. Measurements of sound insulation in buildings and of building elements. Requirements for laboratory test facilities with suppressed flancking transmission, 1999.

[4] EN ISO 140-3. Acoustics. Measurements of sound insulation in buildings and of building elements. Laboratory measurements of airborne sound insulation of building elements, 1997.

[5] UNI EN ISO 140-2. Acoustics. Measurements of sound insulation in buildings and of building elements. Determination, verification and application of precision data, 1994.

[6] UNI CEI EN 45001. Criteri generali per il funzionamento dei laboratori di prova, 1990.

[7] NF S 31-051. Mesure du pouvoir d'isolation acoustique des éléments de costruction et de l'isolement des immeubles. Mesure en laboratoire du puvoir d'isolation acoustique au bruit aérien des éléments de contruction; AFNOR, 1985.

[8] Nordtest Method NT ACOU 062. Acoustics - determination of sound power levels of noise sources-survey method using a reference sound source, 1987.

[9] prEN 1793-3. Road traffic noise reducing devices. Test method for determining the acoustic performance - normalized traffic noise spectrum, 1997.

[10] UNI EN 1793-3. Road traffic noise reducing devices. Test method for determining the acoustic performance - normalized traffic noise spectrum, 1999.

[11] EN ISO 354. Acoustics. Measurement of sound absorption in a reverberation room, 1985.

[12] Barber A. Handbook of noise and vibration control. Amsterdam: Elsevier Advanced Technology, 1992. 